\title{
Role of glycogen-lowering exercise in the change of fat oxidation in response to a high-fat diet.
}

Citation for published version (APA):

Schrauwen, P., van Marken Lichtenbelt, W. D., Saris, W. H. M., \& Westerterp, K. R. (1997). Role of glycogen-lowering exercise in the change of fat oxidation in response to a high-fat diet. American Journal of Physiology (Consolidated), 273((3 Pt 1)), E623-E629.

https://doi.org/10.1152/AJPENDO.1997.273.3.E623

Document status and date:

Published: 01/01/1997

DOI:

10.1152/AJPENDO.1997.273.3.E623

Document Version:

Publisher's PDF, also known as Version of record

\section{Please check the document version of this publication:}

- A submitted manuscript is the version of the article upon submission and before peer-review. There can be important differences between the submitted version and the official published version of record.

People interested in the research are advised to contact the author for the final version of the publication, or visit the DOI to the publisher's website.

- The final author version and the galley proof are versions of the publication after peer review.

- The final published version features the final layout of the paper including the volume, issue and page numbers.

Link to publication

\footnotetext{
General rights rights.

- You may freely distribute the URL identifying the publication in the public portal. please follow below link for the End User Agreement:

www.umlib.nl/taverne-license

Take down policy

If you believe that this document breaches copyright please contact us at:

repository@maastrichtuniversity.nl

providing details and we will investigate your claim.
}

Copyright and moral rights for the publications made accessible in the public portal are retained by the authors and/or other copyright owners and it is a condition of accessing publications that users recognise and abide by the legal requirements associated with these

- Users may download and print one copy of any publication from the public portal for the purpose of private study or research.

- You may not further distribute the material or use it for any profit-making activity or commercial gain

If the publication is distributed under the terms of Article $25 \mathrm{fa}$ of the Dutch Copyright Act, indicated by the "Taverne" license above, 


\title{
Role of glycogen-lowering exercise in the change of fat oxidation in response to a high-fat diet
}

\author{
PATRICK SCHRAUWEN, WOUTER D. VAN MARKEN LICHTENBELT, \\ WIM H. M. SARIS, AND KLAAS R. WESTERTERP \\ Department of Human Biology, Maastricht University, 6200 MD Maastricht, The Netherlands
}

\begin{abstract}
Schrauwen, Patrick, Wouter D. Van Marken Lichtenbelt, Wim H. M. Saris, and Klaas R. Westerterp. Role of glycogen-lowering exercise in the change of fat oxidation in response to a high-fat diet. Am. J. Physiol. 273 (Endocrinol. Metab. 36): E623-E629, 1997.-One of the candidate factors for determining the increase of fat oxidation after a switch from a reduced-fat diet to a high-fat diet is the size of the glycogen storage. Therefore, we studied the effect of low glycogen stores on fat oxidation after a switch from a reducedfat diet to a high-fat diet. Twelve healthy, nonobese males and females (age: $22 \pm 1 \mathrm{yr}$, body mass index: $21.0 \pm 0.7$, maximal power output: $254 \pm 11 \mathrm{~W}$ ) consumed a reduced-fat (RF) diet $(30,55$, and $15 \%$ of energy from fat, carbohydrate, and protein, respectively) three times a day at home for 3 days (days 1-3). On two occasions subjects came to the laboratory on day 3 at 1500 to perform an exhaustive glycogen-lowering exercise (EX), after which they went into the respiration chamber for a 36 -h stay. On one occasion, subjects directly entered the respiration chamber at 1800 for a 36 -h stay. In the respiration chamber they were given either a high-fat (FF) diet $(60,25$, and $15 \%$ of energy from fat, carbohydrate, and protein, respectively) or a RF diet. In both cases they were fed at energy balance. All diets were consumed as breakfast, lunch, dinner, and two or more snacks per day. On the HF treatment, fat oxidation was below fat intake, indicating the slow change of oxidation to intake on a FIF diet. After the HIF + EX treatment, however, fat oxidation matched fat intake. In conclusion, lean subjects are capable of rapidly adjusting fat oxidation to fat intake when glycogen stores are lowered by exhaustive exercise.
\end{abstract}

respiration chamber; glycogen stores; obesity

THE INCIDENCE OF OBESTTY is still increasing in affluent societies. Both increased fat content of the diet and decreased physical activity have been proposed to explain this phenomenon (4). Therefore, much attention has been paid to energy and substrate metabolism in obesity. It was found that weight maintenance requires, in addition to energy balance, balances of the separate macronutrients. For protein and carbohydrate, such balances are maintained within narrow ranges. Fat balance depends more on energy balance (1). Important work in this field is done by Flatt, who has postulated a two-compartment model (8). This model states that, in response to an increase in dietary fat content, fat oxidation can be increased by two mechanisms: 1) glycogen stores can be maintained in a lower range, leading to lower glucose and insulin concentrations between meals, and hence higher fatty acid concentrations and higher rates of fat oxidation, and/or 2) expansion of the adipose tissue mass, which leads to enhanced fat oxidation.
In humans, it has been shown that fat intake does not promote its own oxidation (26). In a previous study we showed that, when dietary fat content is increased, lean subjects are capable of adjusting fat oxidation to fat intake within 7 days (25). In this study, subjects spent 2 days on a reduced-fat diet (30\% energy as fat) and, subsequently, 3 days on a high-fat diet $(60 \%$ energy as fat) in the respiration chamber. After 7 days on the high-fat diet, subjects spent another day in the respiration chamber. Fat oxidation gradually increased on the high-fat diet and equaled fat intake 7 days after the dietary switch. During the first days on the high-fat diet, negative carbohydrate balances were found (on average $-142 \mathrm{~g}$ ). We therefore suggested that declining glycogen stores might be responsible for the gradual increase in fat oxidation. However, other mechanisms such as increased enzymatic capacity for fat oxidation might be responsible for the increase in fat oxidation.

In this study we investigated the role of glycogen stores in the change of fat oxidation in response to a high-fat diet. Glycogen was lowered by means of exercise bouts, and substrate oxidation was measured using a respiration chamber. We hypothesized that the change in fat oxidation in response to an increased fat intake can be accelerated when glycogen stores are low.

\section{SUBJECTS AND METHODS}

\section{Subjects}

The characteristics of the 12 volunteers ( 6 men, 6 women) participating in this study are shown in Table 1 . All subjects were healthy, untrained (not active in any sport, no training history), and nonobese. Subjects' habitual energy intake was $11.0 \pm 0.7 \mathrm{MJ} /$ day, with $34 \pm 1,52 \pm 2$, and $13 \pm 1 \%$ of energy from fat, carbohydrate, and protein, respectively. The study was approved by the Ethical Committee of the Maastricht University, and subjects gave their written informed consent.

\section{Experimental Design}

The experimental design is depicted in Fig. 1, A-C. Each subject followed three different treatments. Treatments were separated by $\geq 1$ wh and were conducted in random order. Each treatment consisted of a 36 -h stay in the respiration chamber. Before all three treatments, subjects were given a reduced-fat diet for consumption at home for 3 days (days 1-3). On two occasions subjects came to the laboratory on day 3 at 1500 to perform an exhaustive glycogen-lowering exercise (EX) and then to enter the respiration chamber at 1800 for a 36 -h stay. In the respiration chamber they were given either a high-fat diet ( $\mathrm{FF}+\mathrm{EX})$ or a reduced-fat diet ( $\mathrm{RF}+\mathrm{EX})$. The RF diet contained $30 \%$ energy as fat, as is often recommended in the prevention of obesity (4). On the third occasion no glycogen-lowering exercise was performed, but subjects directly entered the respiration chamber at 1800 for a $36-\mathrm{h}$ 
Table 1. Subject characteristics

\begin{tabular}{|c|c|c|c|c|c|c|c|}
\hline & Age, yr & Height, m & Woight, kg & Percent Fat & $\mathrm{BMI}, \mathrm{lg} / \mathrm{m}^{2}$ & $\mathrm{~W}_{\max }, \mathrm{W}$ & $\begin{array}{l}W_{17 n x} / x_{g} \\
F P M, W\end{array}$ \\
\hline Total & $21.5 \pm 0.7$ & $1.79 \pm 0.03$ & $66.7 \pm 2.2$ & $19 \pm 3$ & $21.0 \pm 0.7$ & $254 \pm 11$ & $4.71 \pm 0.14$ \\
\hline Males & $20.8 \pm 1.1$ & $1.85 \pm 0.04^{t}$ & $68.0 \pm 3.2$ & $11 \pm 3+$ & $19.8 \pm 0.4$ & $279 \pm 20^{*}$ & $4.66 \pm 0.19$ \\
\hline Females & $22.2 \pm 1.0$ & $1.73 \pm 0.02$ & $65.5 \pm 2.9$ & $27 \pm 1$ & $22.2 \pm 1.1$ & $229 \pm 11$ & $4.77 \pm 0.16$ \\
\hline
\end{tabular}

Values are means \pm SE. BMI, body mass index; $\mathrm{W}_{\mathrm{mnx}}$, maximal power output; FFM, fat-free mass. ${ }^{*} P<0.05, \uparrow P<0.001$ vs. females,

stay, where they were given a high-fat diet (HF). On the morning of day 5 , subjects left the respiration chamber at 0800 .

Maximal power output. One week before the experimental treatment, each subject performed an incremental exhaustive exercise test on an electronically braked cycle ergometer (Lode Excalibur, Groningen, The Netherlands) to determine maximal heart rate and maximal power output $\left(W_{\max }\right)$. Exercise was performed until voluntary exhaustion or until the subject could no longer maintain a pedal rate of $>60 \mathrm{rpm}$. Female subjects started at $50 \mathrm{~W}$ and male subjects at $75 \mathrm{~W}$ for $5 \mathrm{~min}$. Thereafter, workload was increased by $50 \mathrm{~W}$ every 2.5 min. When subjects were approaching exhaustion, as indicated by heart rate and subjective scoring, the increment was reduced to $25 \mathrm{~W}$. In practice, this meant that the last one to three load increments were $25 \mathrm{~W}$. Heart rate was registered continuously using a Polar Sport tester (Kempele, Finland). In each individual $\mathrm{W}_{\max }$ was calculated from

$$
\mathrm{W}_{\text {max }}=\mathrm{W}_{\text {out }}+(t / 150) \times \partial \mathrm{W}
$$

in which $W_{\text {out }}$ is the highest workload completed by the subject, $t$ is the time (in s) performed on the last workload, and $\partial \mathrm{W}$ is the final uncompleted load increment (15).

Glycogen-lowering exercise. After fasting for $2 \mathrm{~h}$, the subjects came to the lab at 1500 to perform a glycogen-lowering oxercise test. After a warm-up at $50 \%$ of their $W_{\text {mix }}$ for $5 \mathrm{~min}$, subjects cycled for 2 min at $90 \%$ of $W_{\max }$ followed by 2 min at $50 \%$ of $\mathrm{W}_{\text {max }}$. This was repeated until subjects were no longer able to perform the high-intensity exercise. The maximal intensity was then lowered to $80 \%$ of $\mathrm{W}_{\text {max }}$. Again, when this intensity could no longer be maintained, the maximal intensity was decreased to $70 \%$ of $W_{\text {max }}$. The test was ended after exhaustion. Subjects were allowed to consume water during exercise. During the exercise heart rate was measured continuously with a Polar Sport tester. Energy expended during the exercise was calculated by assuming a mechanical efficiency of $20 \%$ (11).

\section{Diets}

Before the experiment, subjects filled in a 3-day food intake record to estimate habitual diet composition. Metabolizable energy intake and macronutrient composition of the diet were calculated using the Dutch food composition table (28). In the table metabolizable energy is calculated by multiplying the amount of protein, fat, and carbohydrate with the Atwater factors $(16.74,37.66$, and $16.74 \mathrm{~kJ} / \mathrm{g}$ for carbohydrate, fat, and protein, respectively) (19). The amount of protein, fat, and carbohydrate was multiplied by $0.909,0.948$, and 0.953 , respectively, to correct for digestibility of macronutrients. All experimental diets were consumed as breakfast, lunch, dinner, and two or more snacks per day. The composition of experimental diets is given in Table 2. All snacks had the same macronutrient composition as the experimental diet.

On days 1 and 2 and the first part of day 3 , an RF diet for consumption at home was provided. Subjects were given a fixed amount of food (based on their food intake record) and ad libitum access to snacks. On the evening of day 3 , subjects consumed their dinner and evening snack (either RF or HF) in the respiration chamber. In the $\mathrm{HF}$ treatment, energy intake for dimner and evening snack was fixed at 35 and $15 \%$ of estimated daily energy expenditure $[1.7 \times$ basal metabolic rate (BMR) based on the Harris and Benedict equations; for women: $\mathrm{BMR}=2.74+0.774 \times \mathrm{H}+0.040 \times \mathrm{BM}-0.020 \times \mathrm{A}$, and for men: $B M R=0.28+2.093 \times \mathrm{H}+0.058 \times \mathrm{BM}-$ $0.028 \times \mathrm{A}$, in which BMR is in MJ/day, $\mathrm{H}$ is height in meters, $B M$ is body mass in kilograms, and $A$ is age in years] (12). In the RF+EX and HF+EX treatments, the evening snack had an energy content equal to energy expended during the exercise test. On day 4, subjects were given an amount of energy equal to 1.55 times the sleeping metabolic rate (SMR), as measured during the preceding night. In a previous study it was shown that, with a comparable activity protocol used in the chamber, a physical activity index of 1.58 was reached (20).

A

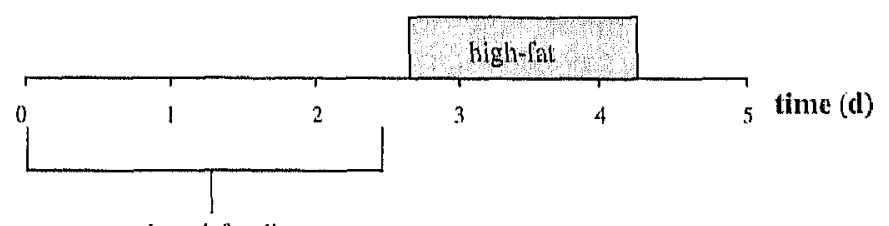

reduced-fitt diet

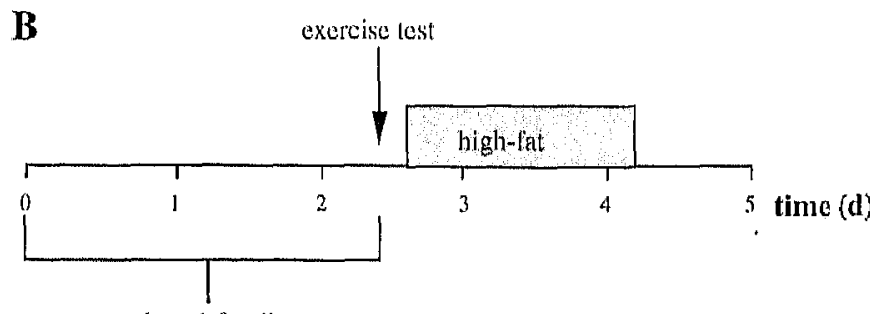

reciucecl-fitt diet

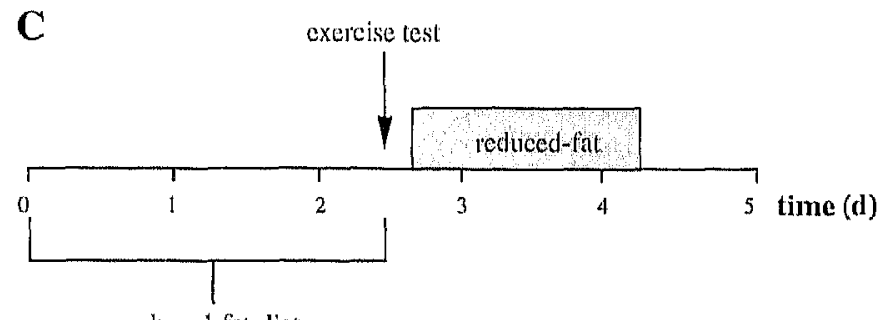

reduced-fat diet

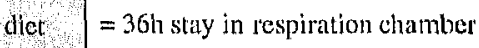

Fig. 1. Experimental design of the 3 different treatments. $A$ : high-fat diet (HF) treatment; $B: \mathrm{HF}$ plus exercise (HF+EX) treatment; $C$ : reduced-fat diet $+\mathrm{EX}(\mathrm{RF}+\mathrm{EX})$ treatment. Time measured in days $(\mathrm{d})$. 
Table 2. Composition of experimental diets

\begin{tabular}{lcc}
\hline & Reduced-Fat Diet & High-Fat Diet \\
\hline Protein & 15 & 15 \\
Carbohydrate & 55 & 25 \\
Fat & 30 & 60 \\
Food quotient & 0.88 & 0.80 \\
\hline
\end{tabular}

Values of protein, carbohydrate, and fat are expressed as \% of total energy.

\section{Procedures}

Body composition. Subjects weighed themselves in the respiration chamber on the morning of days 4 and 5 , without clothing, after voiding, and before eating and drinking. Measurements were done on a digital balance (Seca delta, model 707) with an accuracy of $0.1 \mathrm{~kg}$.

Whole body density was determined by underwater weighing in the morning in the fasted state. Body weight was measured with a digital balance with an accuracy of $0.01 \mathrm{~kg}$ (Sauter, type E1200), Lung volume was measured simultaneously with the helium dilution technique by use of a spirometer (Volugraph 2000, Mijnhardt). Percent body fat was calculated using the equations of Siri (27). Fat-free mass (in $\mathrm{kg}$ ) was calculated by subtracting fat mass from total body mass.

Indirect calorimetry and physical activity. $\mathrm{O}_{2}$ consumption and $\mathrm{CO}_{2}$ production were measured in a whole-room indirect calorimeter (24). The respiration chamber is a $14-\mathrm{m}^{3}$ room furnished with a bed, chair, television, radio, telephone, intercom, wash bowl, and toilet. The room is ventilated with fresh air at a rate of $70-80 \mathrm{l} / \mathrm{min}$. The ventilation rate is measured with a dry gas meter (Schlumberger, type G6, The Netherlands). The concentrations of $\mathrm{O}_{2}$ and $\mathrm{CO}_{2}$ are measured using a paramagnetic $\mathrm{O}_{2}$ analyzer (type Magnos $\mathrm{G} 6$, Hartmann \& Braun, Frankfurt, Germany) and an infrared $\mathrm{CO}_{2}$ analyzer (type Uras $3 \mathrm{G}$, Hartmann \& Braun). Ingoing air is analyzed every $15 \mathrm{~min}$ and outgoing air once every $5 \mathrm{~min}$. The gas sample to be measured is selected by a computer that also stores and processes the data. Energy expenditure is calculated from $\mathrm{O}_{2}$ consumption and $\mathrm{CO}_{2}$ production according to the method of Weir (32).

In the respiration chamber subjects followed an activity protocol consisting of fixed times for brealfast, lunch, and dinner, sedentary activities, and bench-stepping exercise. The bench-stepping exercise was performed for $30 \mathrm{~min}$ at intervals of 5 min of exercise alternated with 5 min of rest, at; a rate of 60 steps per min with a bench height of $33 \mathrm{~cm}$, and was repeated three times a day. Thus subjects exercised for 45 min per day, at a relative low-to-medium intensity. At daytime, no sleeping or other exercise was allowed during the stay in the respiration chamber. All physical activity of the subjects was monitored by means of a radar system based on the Doppler principle.

Urinary nitrogen excretion. During the stay in the respiration chamber urine was collected in two batches, the first from 2000 to 0800 and the second over the subsequent 24 -h interval. Subjects were requested to empty the bladder at 0800 . The urine produced was included in the urine sample of the previous batch. Samples were collected in containers with $10 \mathrm{ml} \mathrm{H}_{2} \mathrm{SO}_{4}$ to prevent nitrogen loss through evaporation; volume and nitrogen concentration were measured, the latter with a nitrogen analyzer (type CHN-O-Rapid, Heraeus).

Twenty-four-hour energy expenditure and substrate oxidation. Subjects stayed in the respiration chamber for $36 \mathrm{~h}$. Data from 2000 on day 3 to 0800 on day 4 are presented to study short-term effects of treatments. For calculation of balances, 24-h energy expenditure (EE) and 24-h respiratory quotient (RQ) were measured from 0800 on day 4 to 0800 on day 5. SMR was defined as the lowest mean EE during three subsequent hours measured between 0000 and 0800 with a minimal activity level as indicated by the radar system.

Carbohydrate, fat, and protein oxidation were calculated using $\mathrm{O}_{2}$ consumption, $\mathrm{CO}_{2}$ production, and urinary nitrogen losses with the equations of Brouwer (5)

Protein oxidation (g/day) $=6.25 \times \mathrm{N}$

Fat oxidation $(\mathrm{g} /$ day $)=1.718 \times \dot{\mathrm{V}}_{2}-1.718 \times \dot{\mathrm{V}} \mathrm{CO}_{2}$ $-0.315 \times P$

Carbohydrate oxidation (g/day)

$$
=4.17 \times \dot{\mathrm{V}}_{\mathrm{CO}_{2}}-2.965 \times \dot{\mathrm{V}}_{2}-0.390 \times \mathrm{P}
$$

where $\mathrm{N}$ is the total nitrogen excreted in urine ( $\mathrm{g} / \mathrm{day}$ ), $\dot{\mathrm{V}} \mathrm{O}_{2}$ is the $\mathrm{O}_{2}$ consumption (l/day), $\dot{\mathrm{V}} \mathrm{CO}_{2}$ is the $\mathrm{CO}_{2}$ production (1/day), and $P$ is protein oxidation (g/day).

\section{Statistical Analysis}

All data are presented as means $\pm \mathrm{SE}$. Equality of $\mathrm{RQ}$ and food quotient (FQ), energy intake, and EE, as well as substrate intake and substrate oxidation, was determined by calculating the 95\% confidence intervals for differences. A nonparametric Wilcoxon test, using a Bonferroni correction, was used to detect any differences in measured parameters between treatments.

\section{RESULTS}

Time until exhaustion during the exercise test was not significantly different between the RF+EX and HF + EX treatments: $71 \pm 4$ and $69 \pm 4$ min, respectively. Also, no difference in EE during the exercise tests was found: $3.4 \pm 0.8$ and $3.5 \pm 0.3 \mathrm{MJ}$ for $\mathrm{RF}+\mathrm{EX}$ and HF + EX treatments, respectively.

Body weight, as measured in the respiration chamber, was not significantly different among any of the treatments (Table 3).

SMR measured during the first night was significantly increased in the RF+EX treatment compared with the HF treatment $(P<0.05)$. In the HF+EX treatment, SMR tended to be increased compared with the FIF treatment $(P=0.06)$. However, SMR measured during the second night was not significantly different among any of the treatments (Table 3). Twenty-fourhour EE (Table 4$)$ and physical activity index $(=24-\mathrm{h}$

Table 3. SMR, PAI, and body weight measured in respiration chamber

\begin{tabular}{|c|c|c|c|c|}
\hline \multirow[b]{2}{*}{ Treatiment: } & \multicolumn{2}{|c|}{$\mathrm{kJ} / \mathrm{min}$} & \multirow[b]{2}{*}{ PAI } & \multirow{2}{*}{$\begin{array}{c}\text { Body } \\
\text { Weight, } \\
\text { leg }\end{array}$} \\
\hline & Night 1 & Night 2 & & \\
\hline$R F+E X$ & $4.62 \pm 0.14$ & $4.42 \pm 0.15$ & $1.60 \pm 0.02$ & $66.8 \pm 2.3$ \\
\hline $\mathrm{HIF}$ & $4.32 \pm 0.14$ & $4.42 \pm 0.15$ & $1.57 \pm 0.03$ & $66.6 \pm 2.3$ \\
\hline $\mathrm{HF}+\mathrm{EX}$ & $4.52 \pm 0.17+$ & $4.44 \pm 0.15$ & $1.59 \pm 0.02$ & $66.7 \pm 2.3$ \\
\hline
\end{tabular}

Values are means \pm SE. SMR, sleeping metabolic rate; PAI, physical activity index; RF and HF, reduced-fat and high-fat diet, respectively; IX, exercise. PAI: 24 -h energy expenditure/24-h SMR, $* P<0.05, \uparrow P=0.056$ vs. HTF. 
Table 4. Energy intake, expenditure, and balance of subjects on 3 different treatments as measured in respiration chamber

\begin{tabular}{lcrr}
\hline Treatment & Intalse & \multicolumn{1}{c}{ Expenditure } & \multicolumn{1}{c}{ Balance } \\
\hline $\mathrm{RF}+\mathrm{EX}$ & $10.02 \pm 0.38$ & $10.19 \pm 0.38$ & $-0.17 \pm 0.19$ \\
$\mathrm{HF}$ & $10.00 \pm 0.37$ & $9.99 \pm 0.32$ & $+0.00 \pm 0.21$ \\
$\mathrm{HF}+\mathrm{EX}$ & $10.04 \pm 0.37$ & $10.17 \pm 0.38$ & $-0.13 \pm 0.16$ \\
\hline
\end{tabular}

Values are means $\pm \mathrm{SE}$ expressed in MJ for a 24-h (8:00 AM-8:00 AM) measurement.

EE/SMR, Table 3) were not significantly different among treatments.

On the evening after the exercise test, subjects were given an amount of energy to compensate for the $\mathrm{EE}$ during the exercise bout. Therefore, of course, a positive energy balance was measured during the first $12 \mathrm{~h}$ in the chamber. However, this positive energy balance was not significantly different between the RF +EX and $\mathrm{HF}+\mathrm{EX}$ treatments $(2.89 \pm 0.2$ vs. $2.90 \pm 0.24 \mathrm{MJ})$. RQ during the first $12 \mathrm{~h}$ in the respiration chamber was $0.843 \pm 0.014,0.846 \pm 0.023$, and $0.803 \pm 0.015$ for the $\mathrm{RF}+\mathrm{EX}, \mathrm{HF}$, and HF + EX treatments, respectively. The $R Q$ was significantly lower in the HF+EX than in the $\mathrm{RF}+\mathrm{EX}$ and HF treatments $(P<0.01)$. In the HF treatment all energy of the positive energy balance $(1.71 \pm 0.19 \mathrm{MJ})$ was stored as fat. In the RF+EX treatment a positive carbohydrate balance of $136.6 \pm$ $22.5 \mathrm{~g}$ and a positive fat balance of $9.7 \pm 9.4 \mathrm{~g}$ were reached, whereas in the HF+EX treatment those values were $+48.7 \pm 21.8$ and $+49.3 \pm 26.6 \mathrm{~g}$ for carbohydrate and fat, respectively. Thus glycogen was more repleted in the $\mathrm{RF}+\mathrm{EX}$ than in the HF+EX treatment and, as a result, differences in glycogen store were obtained.

In all three tests, 24-h energy balance (day 4) was not significantly different from zero. Twenty-four-hour RQ was significantly different among all treatments $(P<$ $0.05)$. RQ was lowest in the $\mathrm{HF}+\mathrm{EX}$ treatment and highest in the RF+EX treatment (Fig. 2). RQ was significantly different from $\mathrm{FQ}$ in the $\mathrm{HF}$ and $\mathrm{RF}+\mathrm{EX}$ treatment $(P<0.05)$. In the $\mathrm{HF}+\mathrm{EX}$ treatment, $\mathrm{RQ}$ and $F Q$ were not significantly different (Fig. 2).

Twenty-four-hour protein oxidation was not significantly different among treatments (Table 5). In the RF +EX treatment, protein intake was significantly higher than in the HF and HF+EX treatments (84 vs. $78 \mathrm{~g} /$ day, Table $5, P<0.05$ ), resulting in a significantly positive protein balance in the $R F+E X$ treatment (Fig. $3, P<0.05)$.

Twenty-four-hour carbohydrate oxidation was significantly different among all treatments, being highest in the RF+EX treatment and lowest in the HF+EX treatment $(P<0.01$, Table 5), resulting in positive carbohydrate balance in the RF+EX treatment and negative carbohydrate balance in the HF treatment (Fig. 3).

Twenty-four-hour fat oxidation was significantly different among all treatments, being lowest in the RF+EX treatment and highest in the $\mathrm{HF}+\mathrm{EX}$ treatment $(P<$ 0.05 , Table 5), resulting in negative fat balance in the
$\mathrm{RF}+\mathrm{EX}$ treatment, positive fat balance in the HF treatment, and zero fat balance in the HF+EX treatment (Fig. 3).

\section{DISCUSSION}

The results of the present study demonstrate that, after a switch from an RF diet to an HF diet under conditions of energy balance, fat oxidation can be increased rapidly to levels that match fat intake when glycogen stores are lowered by exhaustive exercise. After glycogen-lowering exercise in combination with an $\mathrm{HF}$ diet, fat oxidation was equal to fat intake, whereas on the HF diet without glycogen-lowering exercise, fat oxidation was not increased sufficiently to match fat intake. After glycogen-lowering exercise in combination with the RF diet, glycogen was partly repleted and the increase in fat oxidation was less marked, providing another indication of the important role of glycogen content in the regulation of fat oxidation.

Flatt (8) has proposed a model in which he states that, on an HF diet, fat oxidation can be increased by two mechanisms. First, fat oxidation can be raised by maintaining glycogen stores in a lower range. Second, expansion of the fat mass will lead to increase in fat oxidation (2). In our experiment, subjects were fed at energy balance and therefore expansion of the fat mass was negligible. We found that, on the HF diet, fat oxidation was increased sufficiently to equal fat intake when glycogen stores were low. Therefore, our data are in agreement with the model of Flatt and demonstrate the importance of glycogen stores in increasing fat oxidation on an HF diet. In both the RF+EX and the HF +EX treatments, glycogen was lowered by means of exercise. During the first $12 \mathrm{~h}$ in the chamber, carbohy. drate balance was more positive during the RF+EX

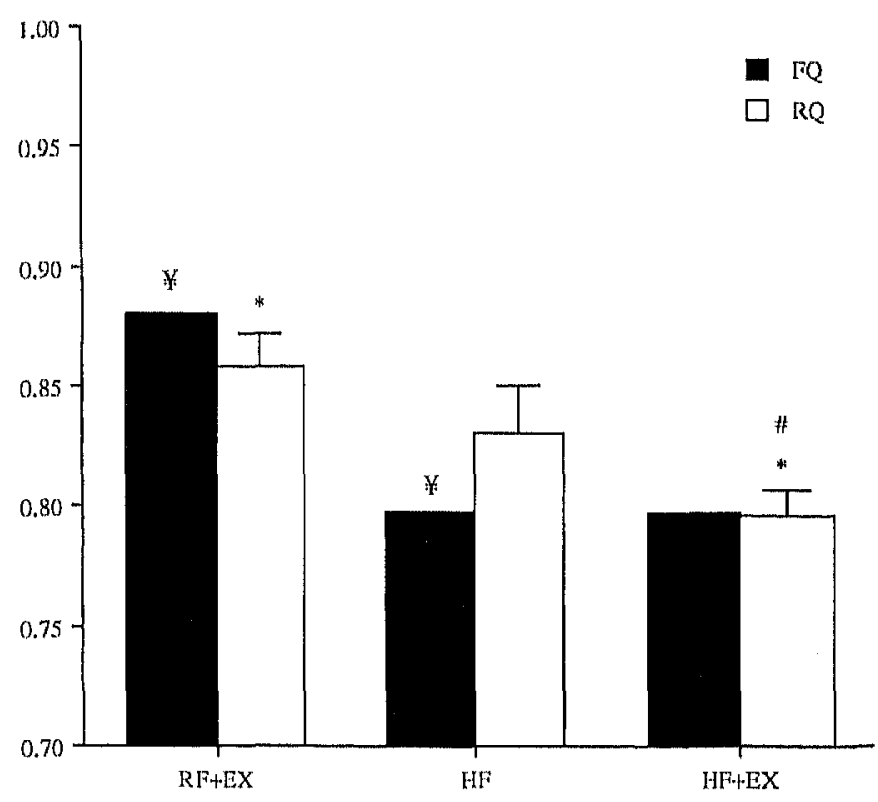

Fig. 2. Twenty-four-hour respiratory quotients (RQ) and food quotients (FQ) as measured in respiration chamber for day 4 (means \pm SE). Significant difference $(P<0.05)$ vs. "HF; \# RF +EX; $R Q$. 
Table 5. Carbohydrate, fat, and protein intake and oxidation of subjects on 3 different treatments as measured in the respiration chamber

\begin{tabular}{|c|c|c|c|c|c|c|}
\hline \multirow[b]{2}{*}{ Treatment } & \multicolumn{2}{|c|}{ CHO } & \multicolumn{2}{|c|}{ Trat } & \multicolumn{2}{|c|}{ Protein } \\
\hline & Intake & Oxidation & Intalke & Oxidation & Intake & Oxidation \\
\hline $\mathrm{RF}+\mathrm{EX}$ & $334 \pm 13^{\sharp}$ & $283 \pm 13^{k+f}$ & $80 \pm 3^{* ⿻ 1}$ & $101 \pm 6^{* * \mid}$ & $85 \pm 3^{* k}$ & $67 \pm 4$ \\
\hline $\mathrm{HF}$ & $160 \pm 6$ & $219 \pm 10 \dagger$ & $160 \pm 6$ & $124 \pm 8 \dagger$ & $76 \pm 5$ & $68 \pm 3$ \\
\hline $\mathrm{HF}+\mathrm{EX}$ & $1.59 \pm 6$ & $149 \pm 6$ & $161 \pm 6$ & $156 \pm 9$ & $77 \pm 4$ & $75 \pm 4$ \\
\hline
\end{tabular}

Values are means \pm SE expressed in g/day (8:00 AM-8:00 AM), CHO, carbohydrate. ${ }^{*} P<0.05$ vs. HF; $\psi^{\prime} P<0.05$ vs. HF + EX.

treatment than during the $\mathrm{HF}+\mathrm{EX}$ treatment $(+137 \mathrm{~g}$ vs. $+49 \mathrm{~g}$ ). When the size of the positive carbohydrate balance and the prior exercise regimen are considered, most likely this positive carbohydrate balance is stored as glycogen. Therefore, glycogen was more repleted in the RF+EX treatment. The difference in fat oxidation between the RF+EX and HF+EX treatment can thus be explained by differences in both glycogen stores and exogenous carbohydrate availability. However, the higher fat oxidation in the HF+EX treatment compared with the HF treatment (same exogenous carbohydrate availability) indicates the important role glycogen stores play in the regulation of fat oxidation.

In this study, we assumed that subjects on the RF diet (which was almost similar to their habitual diet) would have been in substrate balance. This would mean that the glycogen-lowering exercise increased fat oxidation by $21 \mathrm{~g}$ on the RF diet, whereas on the HF diet, fat oxidation was increased by $32 \mathrm{~g}$, the difference most likely due to lower glycogen stores in the HF+EX treatment compared with the RF+EX treatment.

Using indirect calorimetry for the assessment of substrate oxidation requires some precaution. The assumptions involved in using indirect calorimetry to determine substrate utilization have been reviewed by Livesey and Elia (17). They concluded that the accuracy of indirect calorimetry for assessing substrate oxida-

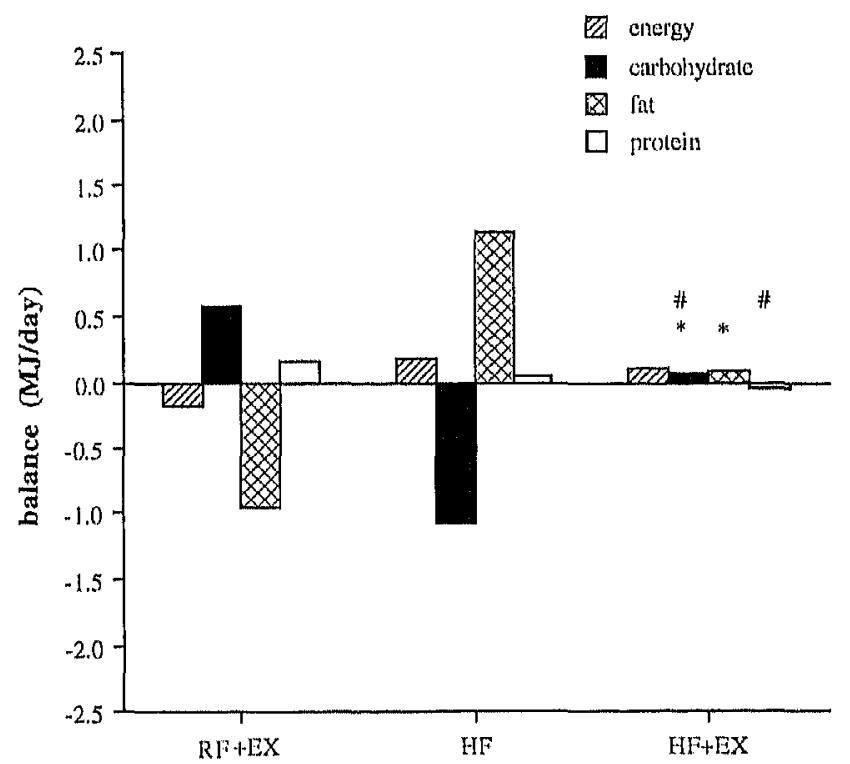

Fig. 3. Twenty-four-hour energy and substrate balances for day 4 as measured in respiration chamber (means \pm SE). Significant difference $(P<0.05$ by Wilcoxon signed-rank test) vs. "HF; \# RF" $+\mathrm{EX}$. tion is at best within $5 \%$ of the true value. Stubbs et al. (29) reported an accuracy of $\pm 20 \mathrm{~g} /$ day and $9.5 \mathrm{~g} /$ day for 24-h carbohydrate and fat oxidation, respectively, as measured in a respiration chamber. Thus changes in substrate oxidation of 64 and $23 \mathrm{~g} /$ day for carbohydrate and fat oxidation, respectively, reported in the present study (Table 5) are well detectable.

In our study we lowered the glycogen stores by means of exercise. It is well known that during exercise at high intensities the major substrate for oxidation is carbohydrate. It has repeatedly been shown in our laboratory by Kuipers et al. (16) and Wagenmakers et al. (31) and in other laboratories $(6,13,18,33)$ that glycogen stores in muscle are significantly decreased both in male and female subjects after exhaustive exercise protocols. The energy expended in both exercise tests was the same, so it can be assumed that glycogen was lowered to the same level. To prevent increases in fat oxidation due to an exercise-induced negative energy balance on the exercise day, energy intake on the first evening in the chamber was based on the energy expended during exercise. This resulted in a positive energy balance that was of the same magnitude in the HF-EX and RF + EX treatments. However, there was a difference in carbohydrate balance. Thus the protocol used must have resulted in differences in glycogen repletion and, therefore, differences in fat oxidation between the HF+EX and RF+EX treatments.

It is possible that the exercise bout itself resulted in other (hormonal) adaptations that accelerated fat oxidation. Bielinski et al. (3) found in their study that $2.5 \mathrm{~h}$ after cessation of exercise, free fatty acid (FFA), glycerol, and glucagon concentrations returned to their control values. This indicates that the (hormonal) disturbances induced by exercise are not long lasting. In our study the elevation in fat oxidation on the $\mathrm{HF}+\mathrm{EX}$ treatment was long lasting. $\mathrm{RQ}$ during sleep, for example, was not significantly different between the 1st and 2 nd nights in the respiration chamber, in either the $\mathrm{RF}+\mathrm{EX}$ or $\mathrm{HF}+\mathrm{EX}$ treatment (data not shown). If the elevation in fat oxidation was an exercise effect other than glycogen lowering, it would be expected that fat oxidation would have returned to lower levels after $36 \mathrm{~h}$. We therefore conclude that the increase in fat oxidation was long lasting and cannot be explained by the exercise itself but can be explained by low glycogen stores,

The mechanism by which low glycogen levels may lead to increased fat oxidation is not clear. Randle et al. (21) introduced the "glucose-fatty acid cycle" in 1963 to 
describe the interaction between fat and carbohydrate oxidation. They suggested that an increased availability of FFA leads to an increased fat oxidation. In our study the glycogen-lowering exercise, especially in combination with the HF diet, might have resulted in lower insulin levels and, thus, less inhibition of lipolysis (7), in turn leading to increased FFA availability and, according to the glucose-fatty acid cycle, increased fat oxidation. However, a recent study in rats showed that glycogen depletion per se does not result in increased FFA uptake and oxidation but increased blood glucose utilization, even at high FFA levels (30). In our experiment, fat oxidation was highest when total carbohydrate availability was low. It therefore seems that carbohydrate oxidation takes priority over fat oxidation and that total carbohydrate availability regulates fat oxidation, for example, through the conversion of acetylCoA into malonyl-CoA, which is an important inhibitor of carnitine palmitoyltransferase, necessary for FFA uptake and thus oxidation (22). This might explain why fat oxidation does not match fat intake on the short term as long as endogenous carbohydrate availability is high. Further studies are necessary to elicit the exact mechanism behind the increase in fat oxidation when glycogen levels are decreased.

Recently, Fleury et al. (10) reported the discovery of a gene that codes for the uncoupling protein-2 (UCP2), which might have a role in diabetes and obesity. UCP2, which is expressed in a number of adult human tissues, might be involved in the regulation of energy balance by influencing $\mathrm{EE}$ and thermogenesis. On an HF diet, UCP2 mRNA levels were significantly increased, and raised levels of FFA may very well activate UCP2 in white adipocytes. Future work must reveal whether this finding is important for the interpretation of our results.

This experiment was performed in healthy, nonobese subjects. It has to be examined whether the same results can be found in obese subjects. Obesity often has been linked to a high fat intake, and therefore much attention has been focused on decreasing the percentage of energy intake derived from fat (14). Because of the high energy density of high-fat foods, this strategy may lead to decreased energy intake and in this way be effective in the treatment of obesity. Another factor that might explain the increased prevalence of obesity in Western societies is a low level of physical activity $(9,23)$. Our results show that acute exercise (accompanied by decreasing glycogen concentration) is an effective method to handle a high fat intake. The same level of physical activity in combination with a RF diet resulted in a negative fat balance. Therefore, regular physical activity can be an effective strategy in the prevention of obesity. Apart from training effects that might stimulate fat oxidation, regular physical activity can prevent obesity by causing glycogen stores to be maintained in a lower range (9).

In conclusion, our results demonstrate that, after switching from a RF diet to a HF diet, lean subjects are capable of adjusting fat oxidation to fat intake when glycogen stores are lowered by exhaustive exercise.
Address for reprint requests: P. Schrauwen, Dept. of Human Biology, Maastricht Univ., PO Box 616, 6200 MD Maastricht, The Netherlands.

Received 10 February 1997; accepted in final form 19 June 1997.

\section{REFERENCES}

1. Abbott, W. G. H., B. V. Howard, L. Christin, D. Freymond, S. Lillioja, V. L. Boyce, T. E. Anderson, C. Bogardus, and E. Ravussin. Short-term energy balance: relationship with protein, carbohydrate, and fat balances. Am. J. Physiol. 255 (Endo. crinol. Metab. 18): E332-E337, 1988.

2. Astrup, A., B. Buemann, P. Western, S. Toubro, A. Raben, and $\mathbf{N}$. J. Christensen. Obesity as an adaptation to a high-fat diet: evidence from a cross-sectional study. Am. J. Clin. Nutr. 59 ; 350-355, 1994.

3. Bielinski, R., Y. Schutz, and E. Jéquier. Energy metabolism during the postexercise recovery in man. Am. J. Clin. Nutr: 42: $69-82,1985$.

4. Bouchard, C. Can obesity be prevented? Nutr. Rev. 54: S125S130, 1996.

5. Brouwer, E. On simple formulae for calculating the heat expenditure and the quantities of carbohydrate and fat oxidized in metabolism of men and animals, from gaseous exchange (oxygen intake and carbonic acid output) and urine-n. Acta Physiol. Pharmacol. Neerlandica 6: 795-802, 1957.

6. Burke, L. M., G. R. Collier, P. G. Davis, P. A. Fricker, A. J. Sanigorski, and M. Hargreaves. Muscle glycogen storage after prolonged exercise: effect of the frequency of carbohydrate feedings. Am. J. Clin. Nutr. 64: 115-119, 1996.

7. Campbell, P. J., M. G. Carlson, J. O. Hill, and N. Nurjhan. Regulation of free fatty acid metabolism by insulin in humans: role of lipolysis and reesterification. Am. J. Physiol. 263 (Eudocrinol. Metab. 26): E1063-E1069, 1992.

8. Flatt, J. P. The difference in the storage capacities for carbolyydrate and for fat, and its implications in the regulation of body weight. Ann. NY Acad. Sci. 499: 104-123, 1987.

9. Flatt, J. P. Glycogen levels and obesity. Int. J. Obes. 20: S1-SI1, 1996.

10. Fleury, C., M. Neverova, S. Collins, S. Raimbault, o. Champigny, C. Levi-Meyrueis, F. Bouillaud, M. F. Seldin, R. S. Surwit, and D. Ricquier. Uncoupling protein-2: a novel gene linked to obesily and hyperinsulinemia. Nat. Gen. 15: 269-273, 1997.

11. Gaesser, G. A., and G. A. Brooks. Muscular efficiency during steady-rate exercise: effects of speed and work rate. $J$. Appl. Physiol. 38: 1132-11.39, 1975.

12. Harris, J. A., and F. G. Benedict. A Biometric Study of Basal Metabolism in Man. Washington, DC: Carnegie Institution, 1919, vol. 190.

13. Ivy, J. L., B. A. Frishberg, S. W. Farrell, W. J. Miller, and W.M. Sherman. Effects of elevated and exercise-reduced muscle glycogen levels on insulin sensitivity. J. Appl. Physiol. 59: 154-159, 1985.

14. Klesges, R. C., L. M. Klesges, C. K. Haddock, and L. H. Eck. A longitudinal analysis of the impact of dietary intake and physical activity on weight change in adults. Am. J. Clin. Nuir: 55: 818-822, 1992 .

15. Kuipers, H., H. A. Keizer, F. Brouns, and W. H. M. Saris. Carbohydrate feeding and glycogen synthesis during exercise in man. Pfügers Arch. 410: 652-656, 1987.

16. Kuipers, H., W. H. M. Saris, F. Brouns, H. A. Keizer, and C. ten Bosch. Glycogen synthesis during exercise and rest with carbohydrate feeding in males and females. Int. J. Sports Med. 10: $S 63-S 67,1989$

17. Livesey, G., and M. Elia. Estimation of energy expenditure, net; carbohydrate utilization and net fat oxidation and synthesis by indirect calorimetry: evaluation of errors with special refierence to the detailed composition of fuels. Am. J. Clin. Nuls: 47: 608-628, 1.988

18. MacDougall, J. D., G. R. Ward, D. G. Sale, and J. R. Sutton. Muscle glycogen repletion after high-intensity intermittent exercise. J. Appl, Physiol. 42: 129-132, 1977. 
19. Miles, C. W. The metabolizable energy of diets differing in dietary fat and fiber measured in humans. e. Nutr: 122: 306-311, 1992.

20. Pannemans, D. L. E., C. V. C. Bouten, and K. R. Westerterp. Twenty-four-hour energy expenditure during a standardized activity protocol in young and elderly men. Eur. J. Clin. Nutr. 49: $49-56,1995$.

21. Randle, P. J., P. B. Garland, C. N. Hales, and E. A. Newsholme. The glucose-fatty acid cycle: its role in insulin sensitivity and the metabolic disturbances of diabetes mellitus, Lancet 1 . $785-789,1963$

22. Saha, A. K., T. G. Kurowski, and N. B. Ruderman. A malonyl-CoA fuel-sensing mechanism in muscle: effects of insulin, glucose, and denervation. Am. J. Physiol. 269 (Endocrinol. Metab. 32): E283-E289, 1995

23. Saris, W. H. M. Physical inactivity and metabolic factors as predictors of weight gain. Nutr. Rev. 54: S110-S115, 1996.

24. Schoffelen, P. F. M., W. H. M. Saris, K. R. Westerterp, and F. ten Floor. Evalution of an automatic indirect calorimeter for measurement of energy balance in man. In: Human Energy Metabolism: Physical Activity and Energy Expenditure. Measurements in Epidemiological Research Based Upon Direct and Indirect Calorimetry. Proceedings of the Euro-nut Congress, edited by A. J. H. van Es. Wageningen, The Netherlands: Stichting Nederlands Instituut voor de Voeding, 1984, p. 51-54.

25. Schratuwen, P., W. D. van Marken Lichtenbelt, W. H. M. Saris, and $\mathbf{K}$. R. Westerterp. Changes in fat oxidation in response to a high-fat diet. Am. J. Clin. Nutr. 66:276-282, 1997.
26. Schutz, Y., J. P. Flatt, and E. Jequier. Failure of dietary fat intake to promote fat oxidation: a factor favoring the development of obesity. Am. J. Clin. Nutr. 50: 307-314, 1989.

27. Siri, W. E. The gross composition of the body. Adv. Biol. Med. Physiol. 4: 239-280, 1956.

28. Stichting-Nederlands-Voedingsstoffenbestand. NEVO Tabel. The Hague, The Netherlands: Voorlichtingsbureau voor de Voeding, 1993.

29. Stubbs, R. J., P. R. Murgatroyd, G. R. Goldberg, and A. M. Prentice. Carbohydrate balance and the regulation of day-today food intake in humans. Am. J. Clin. Nutr. 57: 897-903, 1993.

30. Turcotte, L. P., P. Hespel, and E. A. Richter. Circulating palmitate uptake and oxidation are not altered by glycogen depletion in contracting skeletal muscle. J. Appl. Physiol. 78: 1266-1272, 1995.

31. Wagenmakers, A. J. M., E. J. Beckers, F. Brouns, H. Kuipers, P. B. Soeters, G. J. van der Vusse, and W. H. M. Saris. Carbohydrate supplementation, glycogen depletion, and amino acid metabolism during exercise. Am. J. Physiol. 260 (Endocrinol. Metab. 23): E883-E890, 1991.

32. Weir, J. B. V. New methods for calculating metabolic rate with special reference to protein metabolism. J. Physiol. (Lond.) 109: $1-9,1949$.

33. Zawadzki, K. M., B. B. Yaspelkis III, and J. L. Ivy. Carbohydrate-protein complex increases the rate of muscle glycogen storage after exercise. J. Appl. Physiol. 72: 1854-1859, 1992.

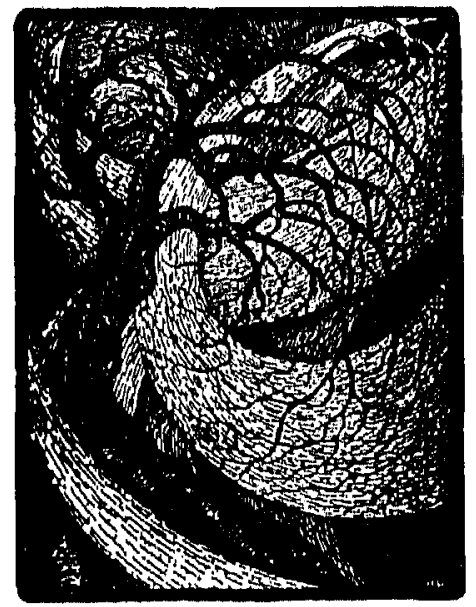

